\title{
Consecutive Case Series of Melanoma Sentinel Node Biopsy for Lymphoseek Compared to Sulfur Colloids
}

\author{
Caitlin Silvestri \\ Thomas Jefferson University \\ Adrienne Christopher, MD \\ Thomas Jefferson University \\ Charles Intenzo, MD \\ Thomas Jefferson University \\ John C. Kairys, MD \\ Thomas Jefferson University \\ Sullogk Kims AAQ additional works at: https://jdc.jefferson.edu/surgeryfp \\ Thomas Jefferson University \\ Part of the Radiology Commons, and the Surgery Commons \\ $\frac{\text { Let us know how access to this document benefits you }}{\text { See next page for additional authors }}$
}

\section{Recommended Citation}

Silvestri, Caitlin; Christopher, MD, Adrienne; Intenzo, MD, Charles; Kairys, MD, John C.; Kim, MD, Sung; Willis, MD, Alliric; and Berger, MD, Adam C., "Consecutive Case Series of Melanoma Sentinel Node Biopsy for Lymphoseek Compared to Sulfur Colloids" (2018). Department of Surgery Faculty Papers. Paper 161.

https://jdc.jefferson.edu/surgeryfp/161

This Article is brought to you for free and open access by the Jefferson Digital Commons. The Jefferson Digital Commons is a service of Thomas Jefferson University's Center for Teaching and Learning (CTL). The Commons is a showcase for Jefferson books and journals, peer-reviewed scholarly publications, unique historical collections from the University archives, and teaching tools. The Jefferson Digital Commons allows researchers and interested readers anywhere in the world to learn about and keep up to date with Jefferson scholarship. This article has been accepted for inclusion in Department of Surgery Faculty Papers by an authorized administrator of the Jefferson Digital Commons. For more information, please contact: JeffersonDigitalCommons@jefferson.edu. 


\section{Authors}

Caitlin Silvestri; Adrienne Christopher, MD; Charles Intenzo, MD; John C. Kairys, MD; Sung Kim, MD; Alliric Willis, MD; and Adam C. Berger, MD 
Revised (7/9/2018)

\title{
Consecutive Case Series of Melanoma Sentinel Node Biopsy for Lymphoseek Compared to Sulfur Colloids
}

\author{
Caitlin Silvestri ${ }^{1}$ \\ Adrienne Christopher, $\mathrm{MD}^{1}$ \\ Charles Intenzo, $\mathrm{MD}^{2}$ \\ John C. Kairys, $\mathrm{MD}^{1}$ \\ Sung Kim, $\mathrm{MD}^{2}$ \\ Alliric Willis, $\mathrm{MD}^{1}$ \\ Adam C. Berger, $\mathrm{MD}^{1}$
}

${ }^{1}$ Sidney Kimmel Medical College at Thomas Jefferson University, Surgery, Philadelphia, PA, USA

${ }^{2}$ Thomas Jefferson University Hospital, Nuclear Medicine/Radiology, Philadelphia, PA, USA

Correspondence: Adam C. Berger-1100 Walnut Street, MOB, Suite 500; Philadelphia, PA 19107.215-955-1622; adam.berger@jeffeson.edu.

Oral Presentation at 2018 Academic Surgical Congress, January 2018.

Short title: Melanoma sentinel node biopsy with Lymphoseek

Data collection was performed by Silvestri and Christopher. Data analysis was performed by Silvestri and Berger. Manuscript was written by Silvestri, Christopher, and Berger with critical review by Intenzo, Kairys, Kim and Willis. Lymphoscintigraphy images were reviewed by Intenzo and Kim. Clinical material was provided by Berger, Kairys, and Willis.

Disclosures: Drs. Berger and Intenzo are on the speaker's bureau for Cardinal Health which distributes Lymphoseek. 


\begin{abstract}
Introduction: Sentinel lymph node biopsy (SLNB) is an important adjunct in the staging of patients with melanoma. Preoperative lymphoscintigraphy (LS) with radiolabeled isotopes is essential to localize sentinel nodes for removal. Our study compared the effectiveness of Lymphoseek $^{\circledR}$ to standard sulfur colloids (SC) in patients with melanoma undergoing SLNB.
\end{abstract}

Methods: We queried our IRB-approved melanoma database to identify 370 consecutive patients who underwent SLNB from 2012-2016 with at least one year of follow up. There were 185 patients in each group. Data points included characteristics of the primary melanoma lymphoscintigraphy, and SLNB. Student's t-test and Chi-Square were used to analyze the data with a p-value of $<0.05$ being considered significant.

Results: Patients were equally matched in regard to age, sex, and primary characteristics of their melanoma. In comparison to SC, Lymphoseek ${ }^{\circledR}$ required lower radiation dosages $(\mathrm{p}<0.001)$, shorter mapping times $(\mathrm{p}=0.008)$, and decreased number of sentinel nodes removed $(\mathrm{p}=0.03)$. There was no difference in the number of patients with positive nodes $(p=0.5)$. Additionally, there were no statistical differences between the two radioactive tracers in regard to the number of patients with false negative SLNB.

Conclusion: Lymphoseek ${ }^{\circledR}$ has the potential to decrease radioactivity and mapping time in patients who need SLNB. With a decrease in the number of nodes removed without loss of sensitivity, there is a potential to avoid unnecessary node removal and thus complications such as lymphedema. Longer follow-up will help to determine if there is any increase in false negative rates despite fewer nodes removed.

Key Words: Melanoma, sentinel lymph node, lymphoscintigraphy, radiocolloids 


\section{INTRODUCTION}

Sentinel lymph node biopsy (SLN) biopsy has been established as the standard of care for staging patients with intermediate-thickness $(>1 \mathrm{~mm})$ cutaneous melanoma. SLN mapping allows for the identification of lymph nodes draining the lymphatic pathway from the primary tumor. Typically, two types of agents are used in this mapping — vital blue dyes such as Lymphazurin which stain the sentinel nodes blue and radiopharmaceuticals which are tracked with lymphoscintigraphy. The most commonly used radiopharmaceuticals used in the United States are large molecular weight radiocolloids, such as ${ }^{99 \mathrm{~m}} \mathrm{Tc}-$ labeled sulfur colloid (SC). Due to their large size, radiocolloids are slowly cleared from the injection site resulting in delayed migration to the lymphatics and this retention may mask regionally located lymph nodes in some instances. Radiocolloids can also be associated with notable injection site pain.

${ }^{99 m}$ Tc-tilmanocept (Lymphoseek ${ }^{\circledR}$ ) is a novel molecular agent which accumulates in lymphatic tissue by binding mannose receptors residing on the surface of lymphatic reticuloendothelial cells (1). It was approved by the Food and Drug Administration for lymphatic mapping in solid tumors in 2014 (1) and is being used more now in patients with breast cancer, melanoma, and squamous cell carcinoma of the head and neck. The novel radiotracer Lymphoseek ${ }^{\circledR}$ provides advantages over blue dyes and radiocolloids due to its structure. Lymphoseek $^{\circledR}$ displays rapid uptake and retention within SLNs, and its small diameter permits rapid injection site clearance. Compared to radiocolloids, Lymphoseek ${ }^{\circledR}$ is also associated with decreased injection site pain (2). In this study, we sought to compare the efficacy of Lymphoseek $^{\circledR}$ to the standard radiocolloids used during SLNB procedures at our institution since we began using Lymphoseek ${ }^{\circledR}$ in July of 2014. 


\section{METHODS}

Following Thomas Jefferson University Institutional Review Board approval with a waiver of informed consent, we performed a retrospective chart review and identified consecutive patients who underwent SLNB between 2012 and 2016 and had at least one year of follow up. The following data points were collected. For the primary tumor, we evaluated the primary site, Breslow thickness, and whether the tumor was ulcerated. For the lymphoscintigraphy, we reviewed reports and films to identify the dosage of radiotracer, the mapping time, and the number of hot spots identified in each patient. Finally, for the SLNB, we recorded the number of sentinel nodes removed and the number of positive sentinel nodes.

\section{SLN Mapping and Biopsy}

All of the procedures were performed by two authors (JCK and ACB). Sentinel lymph node biopsies were performed using the following technique. Patients received intradermal injection of 4 doses of $\sim 150$ microcuries ${ }^{99 \mathrm{~m}} \mathrm{Tc}$ sulfur colloid or 4 doses of $\sim 125$ microcuries of Lymphoseek $^{\circledR}$ on the morning of surgery followed by lymphatic mapping to locate the lymph node drainage basin. All patients underwent full body scanning after injection with SC or Lymphoseek $^{\circledR}$. To determine the mapping time, we reviewed all images and reports to identify how long patients were mapped as well as when the last radiograph was taken (Figure 1). We did not evaluate when the first node was imaged. Intraoperatively, patients received intradermal injection of either $1 \mathrm{ml}$ of isosulfan blue (Lymphazurin ${ }^{\mathrm{TM}} 1 \%$; Tyco International, Exeter, $\mathrm{NH}$ ) or $1 \mathrm{ml}$ of methylene blue at the site of the primary tumor. This was followed by a brief massage of the overlying skin to enhance lymphatic drainage of the injected dye. Radioactivity of the labeled lymph nodes was measured during surgery using a handheld gamma probe. SLN were defined as those containing blue dye, those with the highest counter on the gamma probe, or any 
node that had greater than $10 \%$ radioactivity as compared to the hottest node. All SLN were removed and sent for pathological evaluation.

\section{Pathologic evaluation of lymph nodes}

All identifiable lymph nodes were entirely submitted. Two deeper hematoxylin and eosin (H\&E) stained sections were prepared from the formalin-fixed, paraffin embedded blocks, about 8-12 microns between each level, and depending on size of lymph node, multiple sections were placed on each slide. If no tumor is seen on initial routine sections, then a panel of immunohistochemical antibodies was analyzed including any one or more of the following antibodies: S-100, Melan A, HMB-45, and more recently SOX-10.

Patients were considered to have a false-negative sentinel lymph node biopsy (FNSLNB) if they developed LN recurrence in a LN basin where a sentinel node biopsy was previously performed or in a basin where mapping could theoretically occur. For example, in a patient with a melanoma on the mid-lateral trunk that mapped to the axilla but then recurred in the groin on the same side, we considered that to be a FN-SLNB. We did not consider patients who developed satellite, in-transit, and/or systemic metastases at the same time as a regional LN recurrence to have a FN-SLNB because of the possibility that these metastases could have led to the regional $\mathrm{LN}$ involvement.

\section{Statistical Analysis}

To evaluate the differences between the SC and Lymphoseek ${ }^{\circledR}$ group t-tests were performed with a $p$-value less than or equal to 0.05 being considered significant. Additionally, a chi-squared test was used to evaluate the rate of false negative between the two groups. 


\section{RESULTS}

Between 2012 and 2016, we identified a total of 370 patients who underwent sentinel LN biopsy in this cohort with 185 patients in each group. Characteristics of the entire population are demonstrated in Table 1. When comparing the sulfur colloid (SC) group and the Lymphoseek $^{\circledR}$ group, the average patient age was 59.6 and 60.9 and in both groups, there were more males than females $(60.5 \%$ and $56.2 \%)$, respectively. The distribution of primary melanoma sites was fairly equal with melanomas of the trunk, extremity, and head and neck having equal representation in both groups. There were two and one patients respectively with subungal primary sites. The average Breslow thickness was similar with 2.9 (range $=0.3-37 \mathrm{~mm})$ and 2.6 (range $=0.35-45 \mathrm{~mm})$, respectively. The number of melanomas with ulceration present was also similar between the two groups. The median follow-up time was significantly longer in the SC group which was treated in the earlier years of this study (Table 1).

Being that the two groups were matched in regards to demographic characteristics, we sought to evaluate differences between the groups regarding sentinel lymph nodes and lymphoscintigraphy procedures. (Table 2). All patients underwent full body scanning after injection with SC or Lymphoseek ${ }^{\circledR}$. Images and reports were all reviewed. The dose of radioactivity used for injection was significantly lower in the Lymphoseek ${ }^{\circledR}$ group (503 vs. 580 $\mu \mathrm{Ci}, \mathrm{p}<0.0001)$. The average mapping was significantly lower in the Lymphoseek ${ }^{\circledR}$ group (31 vs. 34 minutes, $\mathrm{p}<0.008$ ). We also evaluated differences in mapping time by determining the number of patients who had mapping for longer than 30 minutes. In the SC group, the vast majority of patients $(n=129,70 \%)$ had mapping times of 30 minutes or greater compared to $109(59 \%)$ in the Lymphoseek $^{\circledR}$ group; this difference was significantly different as well $(\mathrm{p}=0.04)$. 
Additionally, we attempted to identify the number of hot spots per lymph node drainage basin. There was no statistical difference between the two groups in this regard (2.3 vs. 2.4, $\mathrm{p}=0.1$, Table 2). There were four patients in the SC group and six patients in the Lymphoseek $^{\circledR}$ group who did not have any lymph nodes or hot spots identified on mapping $(p=0.75)$. In all of these patients, we were able to identify sentinel nodes with use of the Neoprobe and blue dye. There was no specific pattern regarding the primary sites for these mapping failures (two chest, one arm, one foot for SC group; three arms, one neck, one chest, and an abdominal wall for the Lymphoseek ${ }^{\circledR}$ group)

We found that the average total number of sentinel nodes removed per patient was higher in the SC group compared to Lymphoseek ${ }^{\circledR}$ (2.9 vs 2.5$)$. While this was statistically significant $(p=0.03)$, the clinical significance of this is difficult to determine. If we look at the number of patients with more than 5 SLNs removed, there is a non-significant difference between SC $(n=25)$ and Lymphoseek $(n=17)$. There were 28 patients with positive sentinel

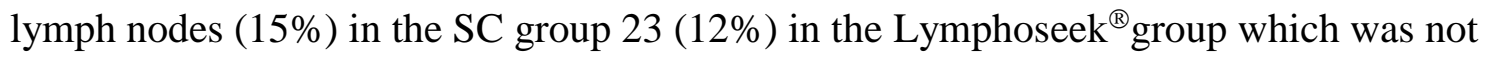
significantly different $(\mathrm{p}=0.5)$. Finally, we looked back to determine whether there was any differences in rates of recurrence in the mapped basin for patients with a negative sentinel lymph node. If we see a difference in this false negative rate, it could indicate some compromise in the integrity of the mapping. Here we found that the false-negative SLNB rates were equal between the two cohorts $((1.6 \%)$ vs. $(1.0 \%), \mathrm{p}=1.0)$. 


\section{DISCUSSION}

The results from this study indicate that Lymphoseek ${ }^{\circledR}\left({ }^{99} \mathrm{Tc}-\right.$ tilmanocept) is able to identify sentinel nodes in patients undergoing lymphoscintigraphy for melanoma in a shorter amount of time and with less radioactivity than patients mapped with ${ }^{9} \mathrm{Tc}-$ Sulfur Colloid. Additionally, with fewer sentinel lymph nodes removed, there is theoretically a decreased likelihood of lymphedema; with short-term follow-up, there is also no decrement in sensitivity with equal number of false negative cases. The number of positive nodes removed per patient was not different, and there was not a significant difference between the percentage of patients with positive nodes.

Despite there not being a difference in the average number of hot spots per basin seen on lymphoscintigraphy, we did find a significant difference in the average number of SLNs removed. This may be explained by Lymphoseek's specificity for CD206 which allows it to stay bound to the first lymph node and not have downstream migration. With fewer secondary nodes taking up the technetium, theoretically, there should be fewer nodes removed. We acknowledge that there is probably not a clinical significant difference between 2.9 and 2.5 nodes. However, it is possible that if you extrapolate this difference out over thousands of patients, this could become a more meaningful clinical difference. The same is true regarding whether this may possibly contribute to the likelihood of lymphedema. It is interesting to note that there was not a significant difference in the number of hot spots seen on lymphoscintigraphy between the groups, yet there was a difference in the number of nodes removed. It is possible that there were

smaller, secondary sentinel nodes that took up the technetium sulfur colloid that were removed at the time of the sentinel node biopsy which led to the increase in the total number of nodes 
removed. In the end, because this is a retrospective study, we do not have a good explanation for this finding and acknowledge that it is a limitation of this study.

${ }^{99}$ Tc-tilmanocept is a novel radiopharmaceutical which accumulates in lymphatic tissue by selectively targeting and binding to CD206 receptors on the surface of macrophages and dendritic cells; these are found in high concentrations in lymph nodes (1). The mannose residue on the tilmanocept serves as a ligand for the CD206 receptor. Furthermore, targeted receptor binding limits its migration into distal lymph nodes (3). The average diameter of the ${ }^{99} \mathrm{Tc}-$ tilmanocept molecule is $7 \mathrm{~nm}$ - this small size allows for rapid lymphatic uptake (1). On the other hand, filtered ${ }^{99} \mathrm{Tc}-\mathrm{SC}$ particles (which is what we and most investigators in the US use) are between 100 and 200nm (1).

The FDA approval of Lymphoseek ${ }^{\circledR}$ for the use in lymphatic mapping for solid tumors followed several clinical trials which demonstrated superior performance over filtered SC. Baker et al performed a study comparing mapping with tilmanocept and blue dye versus SC with blue dye in breast cancer patients (4). They found that fewer SLNs were removed in the tilmanocept patients $(\mathrm{p}<0.0001)$ which is similar to what we found in our study. Two nonrandomized phase III trials compared tilmanocept with blue dye for identification of SLN in melanoma patients. In these studies, tilmanocept identified 232 of 235 blue nodes $(98.7 \%$ concordance); tilmanocept detected 364 nodes only 232 of which were detected by blue dye (64\% reverse concordance) (5). Additionally, in this study, tilmanocept identified more positive nodes than blue dye. Similar results were seen in a phase III study in patients with breast cancer (6). Finally, a multi-center phase III trial in cutaneous or intraoral squamous cell carcinoma of the head and neck demonstrated a high overall accuracy and low false-negative rate for Lymphoseek (7). 
One of the important differences that exist between SC and Lymphoseek ${ }^{\circledR}$ is the differences in injection site pain. Because of the retrospective nature of this trial, we were not able to effectively evaluate that parameter. However, a recent randomized trial in breast cancer patients showed a significant decrease in pain scores for patients injected with Lymphoseek ${ }^{\circledR}$ compared to SC (2). In this study, 52 patients were randomized between the two radiocolloids. The investigators found that at one, two, and three minutes post injection, the Lymphoseek $^{\circledR}$ patients had significantly lower pain scores using the visual analog scale (2). Other investigators have attempted to ameliorate the pain associated with SC injection with addition of lidocaine and bicarbonate to SC (8), separate lidocaine injection (9), or topical anesthetic cream (10) with mixed success.

It is not completely clear why SC induces significantly more pain at the injection site. It was thought that this may be due to the $\mathrm{pH}$ of the agents. However, in the Stojadinovic study, there was no change in pain scores when the $\mathrm{pH}$ of $\mathrm{SC}$ was altered by mixing with bicarbonate (8). One possible reason for the increased pain could be the particle size. The small size of Lymphoseek $^{\circledR}$ particles allows for their rapid transit away from the injection site. Additionally, it is postulated that the larger size of the SC particles may increase the stretch on the nocioceptive pain receptors in the dermis leading to patients experiencing a more intense pain (2).

In regards to shorter mapping times, even though we found a significant difference in mapping times, in reality, there was only a three minute difference. In previously unpublished work from our institution (presented at the 2015 meeting of the Radiologic Society of North America), we found that all 34 patients evaluated had reached the maximum number of identified lymph nodes at 20 minutes as opposed to the $40-45$ minutes that most patients with SC were undergoing imaged. Additionally, when we look at our data set, in the SC group, the vast 
majority of patients had mapping times of 30 minutes or greater compared to the Lymphoseek ${ }^{\circledR}$ group; this difference was significantly different as well $(\mathrm{p}=0.04)$. It is our hope that now that we have established our experience with Lymphoseek ${ }^{\circledR}$ that we can cut short our mapping times at a maximum of 20 minutes. This has the ability to move patients through the system faster with fewer operating room delays and greater patient satisfaction. It is not our routine practice to have patients undergo lymphoscintigraphy the day before their operation because in our academic referral practice, the majority of our patients live a considerable distance away.

We would like to acknowledge several limitations of our study. First of all, this is a nonrandomized study which relied on a consecutive series of patients from before and after the time that our institution switched over to using Lymphoseek ${ }^{\circledR}$ exclusively. Secondly, our follow-up times for the Lymphoseek ${ }^{\circledR}$ patients are significantly shorter (25.2 versus 5.4 months) because these patients were only operated on in the last 3 years. Even though our false-negative rate was no different between the two groups, this may change with longer follow-up in the Lymphoseek ${ }^{\circledR}$ group. Finally, our mapping times are pulled from radiology reports. We did not go back to prospectively evaluate every lymphoscintigraphy study to determine whether there was additional benefit in the number of nodes identified with longer mapping times. We did not perform a formal cost analysis in this study. The cost of Lymphoseek ${ }^{\circledR}$ is significantly more than sulfur colloid ( $\$ 522.00$ vs. $\$ 74.18$ ). Our hope is that with more experience we will be able to have patients go through the Nuclear Medicine Department faster with less pain, and this will justify the increased cost.

In conclusion, it is felt that the ideal lymph node mapping agent should exhibit rapid clearance from the injection site, rapid uptake within the first draining lymph node as well as low 
uptake by the remaining lymph nodes. It should also have a low radiation dose and absorption (11). This study, albeit a small non-randomized one, has demonstrated that Lymphoseek ${ }^{\circledR}$ demonstrates these characteristics. Our institution is using this agent for mapping in all melanoma, Merkel Cell carcinoma, and most breast cancer patients.

\section{REFERENCES}

1. Surasi DS, O'Malley J, Bhambhvani P 99mTc-Tilmanocept: A Novel Molecular Agent for Lymphatic Mapping and Sentinel Lymph Node Localization. J Nucl Med Technol 2015:43:87-91.

2. Unkart JT, Baker JL, Hosseini A, Hoh CK, Wallace MS, et al. Comparison of Post-injection Site Pain Between Technetium Sulfur Colloid and Technetium Tilmanocept in Breast Cancer Patients Undergoing Sentinel Lymph Node Biopsy. Ann Surg Oncol 2015:22 Suppl 3:S559-565.

3. Vera DR, Wallace AM, Hoh CK, Mattrey RF A synthetic macromolecule for sentinel node detection: (99m)Tc-DTPA-mannosyl-dextran. J Nucl Med 2001:42:951-959.

4. Baker JL, Pu M, Tokin CA, Hoh CK, Vera DR, et al. Comparison of [(99m)Tc]tilmanocept and filtered $[(99 \mathrm{~m}) \mathrm{Tc}]$ sulfur colloid for identification of SLNs in breast cancer patients. Ann Surg Oncol 2015:22:40-45.

5. Sondak VK, King DW, Zager JS, Schneebaum S, Kim J, et al. Combined analysis of phase III trials evaluating [(9)(9)mTc]tilmanocept and vital blue dye for identification of sentinel lymph nodes in clinically node-negative cutaneous melanoma. Ann Surg Oncol 2013:20:680-688. 
6. Wallace AM, Han LK, Povoski SP, Deck K, Schneebaum S, et al. Comparative evaluation of $[(99 \mathrm{~m}) \mathrm{tc}] \mathrm{tilmanocept}$ for sentinel lymph node mapping in breast cancer patients: results of two phase 3 trials. Ann Surg Oncol 2013:20:2590-2599.

7. Agrawal A, Civantos FJ, Brumund KT, Chepeha DB, Hall NC, et al. [(99m)Tc]Tilmanocept Accurately Detects Sentinel Lymph Nodes and Predicts Node Pathology Status in Patients with Oral Squamous Cell Carcinoma of the Head and Neck: Results of a Phase III Multiinstitutional Trial. Ann Surg Oncol 2015:22:3708-3715.

8. Stojadinovic A, Peoples GE, Jurgens JS, Howard RS, Schuyler B, et al. Standard versus pHadjusted and lidocaine supplemented radiocolloid for patients undergoing sentinel-lymphnode mapping and biopsy for early breast cancer (PASSION-P trial): a double-blind, randomised controlled trial. Lancet Oncol 2009:10:849-854.

9. Hawkins AS, Yoo DC, Movson JS, Noto RB, Powers K, et al. Administration of subcutaneous buffered lidocaine prior to breast lymphoscintigraphy reduces pain without decreasing lymph node visualization. J Nucl Med Technol 2014:42:260-264.

10. O'Connor JM, Helmer SD, Osland JS, Cusick TE, Tenofsky PL Do topical anesthetics reduce periareolar injectional pain before sentinel lymph node biopsy? Am J Surg 2011:202:707-711; discussion 711-702.

11. Tokin CA, Cope FO, Metz WL, Blue MS, Potter BM, et al. The efficacy of Tilmanocept in sentinel lymph mode mapping and identification in breast cancer patients: a comparative review and meta-analysis of the (9)(9)mTc-labeled nanocolloid human serum albumin standard of care. Clin Exp Metastasis 2012:29:681-686. 


\section{TABLES AND FIGURES}

Table 1. Patient Demographics and Summary Statistics

\begin{tabular}{|c|c|c|}
\hline & Sulfur Colloid & Lymphoseek \\
\hline $\mathbf{N}(\%)$ & $185(50 \%)$ & $185(50 \%)$ \\
\hline $\begin{array}{l}\text { Age, years } \\
\text { (average, range) }\end{array}$ & $59.6(18-89)$ & $60.9(24-87)$ \\
\hline \multicolumn{3}{|l|}{ Sex } \\
\hline Male & 112 & 104 \\
\hline Female & 72 & 81 \\
\hline (Male: Female) & $1.5: 1$ & $1.3: 1$ \\
\hline Breslow, mm (average) & 2.9 & 2.6 \\
\hline \multicolumn{3}{|l|}{ Presence of Ulceration } \\
\hline Ulcerated & 48 & 43 \\
\hline Non-ulcerated & 135 & 130 \\
\hline \multicolumn{3}{|l|}{ AJCC Stage Group } \\
\hline Ia & 28 & 22 \\
\hline $\mathrm{Ib}$ & 71 & 75 \\
\hline IIa & 20 & 33 \\
\hline IIb & 27 & 24 \\
\hline IIc & 11 & 8 \\
\hline IIIa & 12 & 14 \\
\hline IIIb & 16 & 9 \\
\hline \multicolumn{3}{|l|}{ Primary Site } \\
\hline Head/neck & 20 & 22 \\
\hline Trunck & 85 & 76 \\
\hline Extremity & 87 & 86 \\
\hline Subungal & 2 & 1 \\
\hline $\begin{array}{l}\text { Median Follow-up Time } \\
\text { (months) }\end{array}$ & 25.2 & 5.4 \\
\hline
\end{tabular}


Table 2. Mapping and SLN Biopsy Characteristics

\begin{tabular}{|c|c|c|c|}
\hline & $\begin{array}{l}\text { Sulfur Colloid } \\
(n=185,50 \%)\end{array}$ & $\begin{array}{l}\text { Lymphoseek } \\
(\mathrm{n}=185,50 \%)\end{array}$ & p value \\
\hline $\begin{array}{l}\text { Average Dosage, } \\
\text { uCi }\end{array}$ & 580.5 & 503 & $<0.0001$ \\
\hline $\begin{array}{l}\text { Average Mapping } \\
\text { Time, minutes } \\
\text { (range) }\end{array}$ & $\begin{array}{l}33.6 \\
(5-65)\end{array}$ & $\begin{array}{l}30.7 \\
(10-60)\end{array}$ & 0.008 \\
\hline $\begin{array}{l}\text { \# of patients with } \\
\text { mapping > } 30 \mathrm{~min}\end{array}$ & $129(70 \%)$ & $109(59 \%)$ & 0.04 \\
\hline $\begin{array}{l}\text { Average number of } \\
\text { hot spots/basin }\end{array}$ & 2.3 & 2.4 & 0.10 \\
\hline $\begin{array}{l}\text { Average total } \\
\text { number SLN } \\
\text { removed }\end{array}$ & 2.9 & 2.5 & 0.035 \\
\hline $\begin{array}{l}\text { Number patient } \\
\text { with + sentinel } \\
\text { nodes }\end{array}$ & $28(15.1 \%)$ & $23(12.4 \%)$ & 0.5 \\
\hline $\begin{array}{l}\text { Number of False } \\
\text { Negatives }\end{array}$ & 3 & 2 & $\mathrm{P}=1.0$ \\
\hline
\end{tabular}

